\title{
Unravelling ground stone life histories: the spatial organization of stone tools and human activities at LN Makriyalos, Greece
}

\author{
Christina Tsoraki \\ Department of Archaeology, University of Sheffield, UK \\ c.tsoraki@sheffield.ac.uk
}

\begin{abstract}
Unlike previous studies of ground stone technology in the Greek Neolithic, this paper follows a more contextualised approach by looking at contexts of deposition of ground stone from Late Neolithic Makriyalos, Northern Greece. The patterns attested in the distribution of ground stone objects between domestic and communal areas will be discussed in terms of the spatial and social contexts of tool use, curation and deposition, contributing to wider discussions about the way acts of production, consumption and discard were structured within different contexts of social practice.

IZVLEČEK - Ta članek se, v nasprotju s prejšnjimi študijami tehnologije brusov v grškem neolitiku, ukvarja $z$ depozicijskimi konteksti mlajšeneolitskih brusov iz Makriyalosa v severni Grčiji. Vzorce distribucij brusov med družinskimi in komunalnimi območji analiziramo z vidika prostorskih in socialnih kontekstov uporabe ter hranjenja orodij. Razpravljamo o tem, kako so bili produkcija, potrošnja in odpad strukturirani v kontekstov različnih socialnih praks.
\end{abstract}

KEY WORDS - ground stone implements; contextual approach; Northern Greece; Late Neolithic Makriyalos; household; communal areas

\section{Introduction}

In common with other technologies, ground stone objects must be studied contextually in order to gain insight into the way(s) they were used and perceived by their contemporary users. In the case of the Greek Neolithic, a key research issue is the nature of early farming society and, in particular, the suggested emergence of individual households and the interplay between domestic and communal scales of organisation (Halstead 1999; Kotsakis 1999; Tomkins 2004). A contextual analysis of ground stone thus has potential to contribute to the understanding not only of this class of artefacts, but also of the ways in which their production, consumption and discard were structured within different forms of social practice, within daily domestic activities $v s$. periodic gatherings of a more communal character, for example. To date, however, the nature of lithic technology and the value of lithic implements within
Neolithic societies in Greece have been discussed in rather general terms (see Perlès 1992) and have not been explored at the scale of a single settlement. Systematic studies have not been undertaken of the contexts of deposition of ground stone artefacts and of their spatial association with other sets of material culture.

Studies of excavated ground stone assemblages from prehistoric sites in Greece have focussed mainly on typological and technological issues, at least in part because of the restrictions imposed by sample size (see, for instance, the assemblages from Achilleion in Thessaly [Winn and Shimabuku 1989] and Dikili Tash in Macedonia [Séfériadès 1992]). In addition, some of the largest published assemblages come from multi-period surface survey projects and so offer neither chronological nor intra-site contextual 
control, as for example the 304 ground stone artefacts recorded by the Argolid Exploration Project (Kardulias and Runnels 1995) or the assemblage collected by the Lakonia Survey (Carter and Ydo 1996). The ground stone assemblage from large-scale excavations at Late Neolithic Makriyalos in Northern Greece is the largest such assemblage from prehistoric Greece (c. 8800 artefacts) and presents an exceptional opportunity for contextualised analysis to enhance understanding of both ground stone technology and human society in Neolithic Greece.

In this paper, the ground stone assemblage from Makriyalos will be placed in context, and the spatial distribution of tools and tool-related activities will be investigated. Contextual analysis of the Makriyalos assemblage, which is still in progress, has been conducted at various spatial scales, that may reflect different scales of social interaction (household, local community, regional community). To quote Jones (2002.83), 'what we are interested in, then, is how material culture is used to create and maintain meaningful social relations that affirm the definition of identity and belonging at individual, local and wider scales'.

\section{The Site}

The Neolithic site of Makriyalos is one of the largest flat-extended settlements in Macedonia, Northern Greece (Fig. 1). The estimated size of the settlement is $c .50$ hectares, while the excavated area spreads over six hectares. Two phases of Late Neolithic occupation have been identified: Makriyalos I dated to the early Late Neolithic (5300-5000/4900 BC) and Makriyalos II dated to the later Late Neolithic (49004600/4500 BC) (Pappa and Besios 1999b.177180). Makriyalos I was surrounded by a double ditch (Ditches Alpha \& Beta) enclosing an area estimated at 28 ha, while a third ditch (Ditch Gamma) within this enclosure may represent an internal boundary. The enclosure was occupied by loose groups of pits, the larger of which have been interpreted mainly as pit-dwellings. Fire installations were found in separate pits outside the houses (Pappa and Besios 1999a). Another feature identified are borrow pits up to $30 \mathrm{~m}$ in diameter, used initially to mine bedrock (Pappa et al. 2004) (Fig. 2). Makriyalos II is characterised mainly by a densely occupied habitation area with pit structures, but also rectilinear buildings.

The ditches seem to have played a very important role in the communal life of Makriyalos I, because

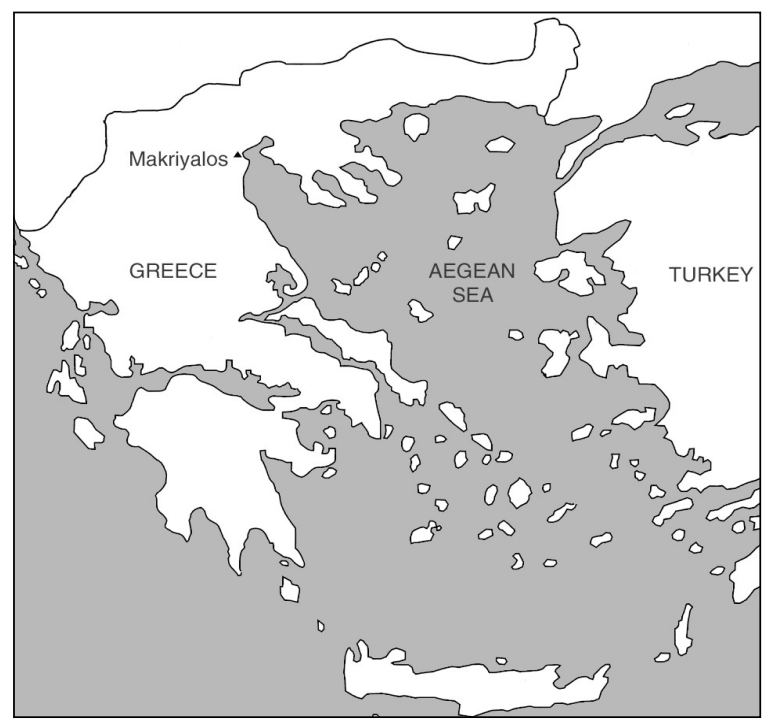

Fig. 1. Map of Greece showing the location of Makriyalos.

they define the boundaries of the settlement and also represent large scale earthworks that would have required the investment of large amounts of energy and probably the mobilisation of many people for their original construction and subsequent reworking (Pappa and Besios 1999a). Ditch A also represents the main burial ground in Makriyalos I (Triantaphyllou 2001), a function that perhaps stressed its communal character by 'defining symbolically a local community' (Pappa et al. 2004.18).

Borrow pits, similar to ditches, have been interpreted as loci of communal character due to the volume of material they have yielded. The study of stratigraphic, faunal and ceramic data from one of these borrow pits - Pit 212 - suggests that its exceptionally rich fill accumulated within months, or just a few years, perhaps from large-scale feasting episodes (Pappa et al. 2004.22). Pit 212 yielded $25 \%$ of the ground stone objects from phase I and represents the largest concentration of ground stone artefacts within this phase. Both ditches and borrow pits thus seem to represent features of a communal character where community identities were forged and maintained.

Because Makriyalos I offers the clearest distinction between and most abundant evidence for both domestic and communal scales of activity, this paper will focus on the material that has been attributed to this phase.

\section{Ground stone technology}

The Makriyalos I ground stone assemblage consists of 5308 artefacts in total, which have been attribu- 
ted to seven main categories: edge tools (17.6\%), grinding/abrasive tools $(65.7 \%)$, percussive tools $(0.8 \%)$, perforators $(0.5 \%)$, multiple-use tools $(2.4 \%)$, ornaments $(0.8 \%)$ and miscellaneous (1.2\%). Artefacts that survive in a fragmentary state and could not be attributed to a specific tool category have been recorded as 'indeterminate' (11.1\%) (Tab. 1).

The grinders from Makriyalos, the upper handheld mobile grinding tools, represent the products of an expedient technology; they are primarily made of marble cobbles and pebbles that come from nearby streams, and have no evidence of manufacture or modification. Grinding slabs, the lower passive grinding tools (Wright 1992), are made from more distant raw materials, mainly sandstone with well-cemented grains, schist and gneiss. They are roughly shaped and there is some evidence for rejuvenation by repecking of heavily used/worn-out use-faces (Tsoraki in prep.).

Edge tools, i.e. tools that have acquired an edge through deliberate modification (axes, adzes, chisels), are made of raw materials from non-local sources, mainly serpentinite and igneous rocks, and are the products of a formalised production sequence. Great time and effort was invested in the production of edge tools, as demonstrated by the high level of polishing on all tool surfaces, indicating that smooth and often lustrous surfaces were a desirable trait (Tsoraki forthcoming). Furthermore, edge tools are also the category with the greatest time invested in maintenance and repair, with evidence, often for more than one episode on the same tool, of the timeconsuming processes of resharpening and sawing. Sawing was characterised by great attention to detail and precision, as indicated by the sequence of steps followed during the refashioning of edge tools using this technique. Unfinished examples in the Makriyalos assemblage indicate that initially a shallow groove

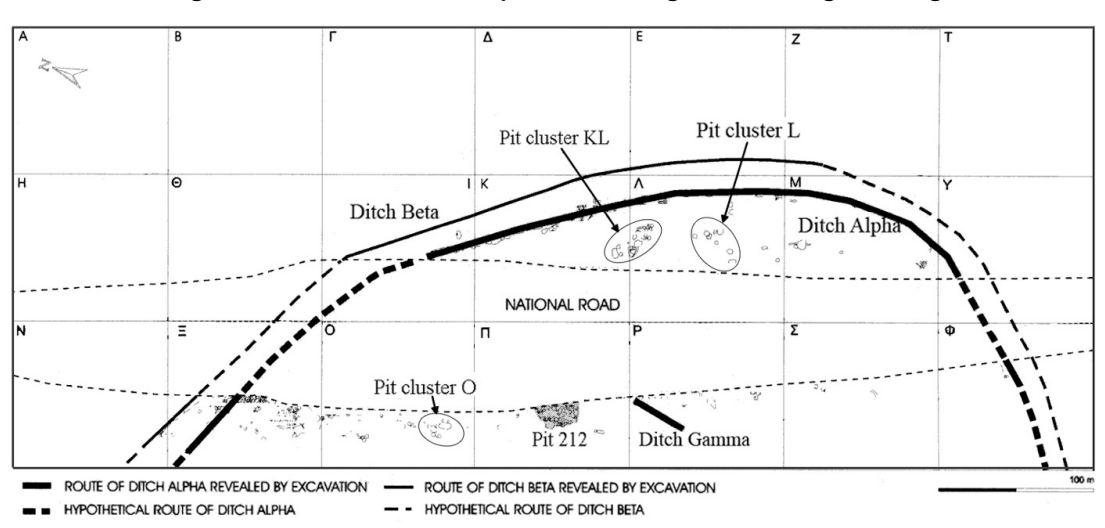

Fig. 2. Plan of Makriyalos I settlement, indicating the location of main features mentioned in the text (after Pappa et al. 2004.17 fig. 2.1). was created, probably with a flint blade, to define where the tool would be cut. Then, using stone slabs and other abrasives (e.g., quartz sand), the tool was sawn by grinding, and quite often two opposed grooves were created so as to control the eventual snapping of the tool in half (Fig. 3). Efforts to erase traces of sawing by re-polishing/re-grinding the remaining lips of the groove again imply interest in the visual appearance of these tools (Tsoraki in prep.).

\section{Ground stone in private and public areas: com- parison between habitation contexts, the ditch system and 'borrow pits'}

As can be seen in Figure 4 most of the material attributed to Makriyalos I comes from stratified contexts, while all three general context types - habitation, ditches, borrow pits - have yielded large assemblages, allowing meaningful comparisons between private and public areas of activity. Of 5308 objects attributed to Makriyalos I, the vast majority ( $>80 \%$ ) comes from communal areas, whereas only $13.0 \%$ of ground stone products have been attributed to habitation areas.

All seven general tool categories occur within ditches, borrow pits, and the habitation area, and in most cases they are distributed rather evenly among the different contexts (Fig. 5). Edge tools and grinding/abrasive tools, however, present distinct patterns of deposition. Edge tools occur more frequently in habitation areas and less frequently in borrow pits and ditches. Grinding/abrasive tools, on the other hand, are encountered mainly in the ditch system and borrow pits, making up almost $80 \%$ of the material from these contexts, as compared with $60 \%$ in domestic contexts (Fig. 5).

More interesting patterns emerge when edge and grinding/abrasive tools are broken down into subcategories. All sub-categories of edge tools (axes, adzes, chisels) occur more frequently in habitation contexts, but grinding/abrasive tools present greater variation in contexts of deposition. Pestles and abraders, though admittedly the sample size is very small, are encountered more frequently within habitation contexts, whereas grinding slabs are relatively more frequent in borrow pits and the ditch system 
than in the habitation area. Grinders, however, are attested twice as frequently in the ditch system as in domestic contexts (Fig. 6). It should also be noted that the only three mortars found in Phase I come from communal areas, two from borrow pit 212 and one from Ditch Gamma.

This evident preference for the deposition of certain tool types in certain areas of the settlement (edge tools in habitation; grinders in ditches; grinding slabs in communal areas) may be further explored in relation to other attributes such as raw materials, fragmentation patterns and degree of use.

Edge tools, grinding slabs and grinders differ little between the three context types in terms of dimensions, morphological characteristics, fragmentation patterns, and degree of use and maintenance. The raw materials used for edge tools, grinding slabs and grinders are also similar between domestic and communal contexts. Marble grinders occur more frequently in the ditch system and borrow pits, however, whilst the grinders from the habitation levels present greater variability in raw materials with quartz and igneous rocks appearing much more frequently here than in the other two context types. Although similar manufacturing techniques are encountered in all three context types, highly polished edge tools occur more frequently in the ditches, while tools with lower quality of polishing are more frequent in habitation contexts.

\section{Investigating activity related to ground stone within the domestic arena}

Apart from the comparison between domestic and communal areas, the spatial analysis of the Makriyalos I assemblage was conducted at a finer level to explore how the production and consumption of ground stone was organised and practised within everyday life. 691 ground stone objects have been attributed to Makriyalos I habitation contexts. The vast majority has been attributed to specific pits, whilst only 144 objects come from units generally attributed to habitation areas $(21.0 \%)$. The pits could be grouped in clusters, the main ones being pit clusters KappaLamda (KL), Lamda (L), and Omikron (0), with 123, 64 and 87 ground stone objects respectively (Fig. 2). In addition to these clusters, relatively large concentrations of materials have been attested in the single pits $251(\mathrm{n}=50), 258(\mathrm{n}=46)$ and $281(\mathrm{n}=26)$.

Comparison of these sub-assemblages reveals a rather uniform picture: apart from the complete $a b$ -

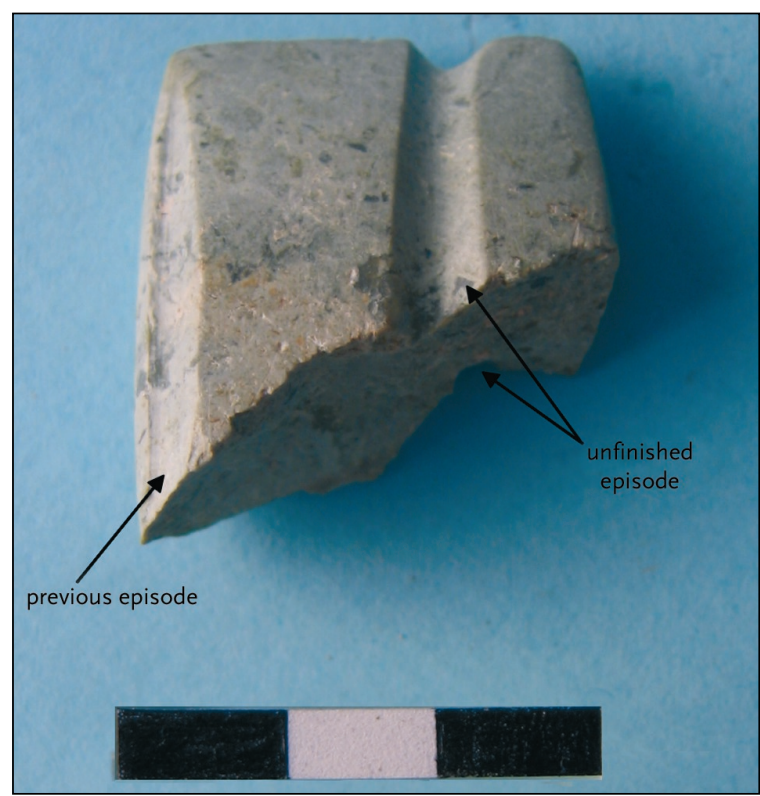

Fig. 3. Edge tool with evidence of two episodes of sawing.

sence of perforators and extreme rarity of percussive tools, all general object categories are encountered in all pit clusters; edge tools and grinding/abrasive tools, in particular grinding slabs, are distributed relatively evenly between the three main clusters of pits, while the ground stone from the pit clusters also exhibit great similarity in terms of morphological characteristics, manufacturing techniques, degree of use and fragmentation patterns. In terms of raw materials, a wide range of rock types attributed to all three geological categories is witnessed in the three clusters and single pits. The presence of similar raw materials within the different clusters could potentially indicate that the different households exploited similar or even the same natural resources.

This homogeneity in the distribution of ground stone material reaffirms the excavators' interpretation of these spaces as places of analogous character (habitation areas). The implication that the same activities were practised in various areas within the site parallels a similar suggestion concerning the distribution of knapped stone tool types and tool-related activities between individual pits and/or pit clusters of the Makriyalos II habitation area (Skourtopoulou 2006).

Grinding activities seem to have been among the regular tasks practised in the small clusters of pits, probably within the pits or in close proximity to them. The portable character of the tools is indicated by the relatively small size of the grinding slabs 
that could easily have been moved, e.g., from inside to outside or vice versa, depending on circumstances (e.g., weather, tasks to be performed, the mood of the person to perform the task) (for a similar suggestion see also Baysal and Wright 2005). Grinding slabs could have been used for different grinding activities (grain processing, mineral processing, etc.), potentially accounting for the presence of more than one use-face on the same tool. In fact, a number of grinding tools show traces of red colour on their usefaces that could relate to the processing of minerals.

Edge tools represent the second most commonly attested category of objects within the clusters of pits. As with grinding slabs, edge tools are versatile and could have been used for a variety of tasks, such as light and heavier woodworking, tree felling and clearing shrubbery, butchery, and bone working, while other uses such as digging and bow-making cannot be excluded (Blackwood 1950.23; Edmonds 1995. 53; Skeates 1995.288; Perlès 200.232).

In addition, the presence of debitage, polishers and grooved abraders confirms that the habitation area was not restricted to the processing of edible substances, but was also used for the production and repair of tools and for the production of other types of material culture such as pottery and edge tools. This is further supported by the presence of tools that show evidence for on-going manufacture and maintenance processes (repecking, resharpening, sawing) within pits of phase I, such as pit 93-96 and pit 95121 in pit-group 0.

These observations are consistent with the organisation of grinding, woodworking and other activities by small social units or households in phase I Makri-

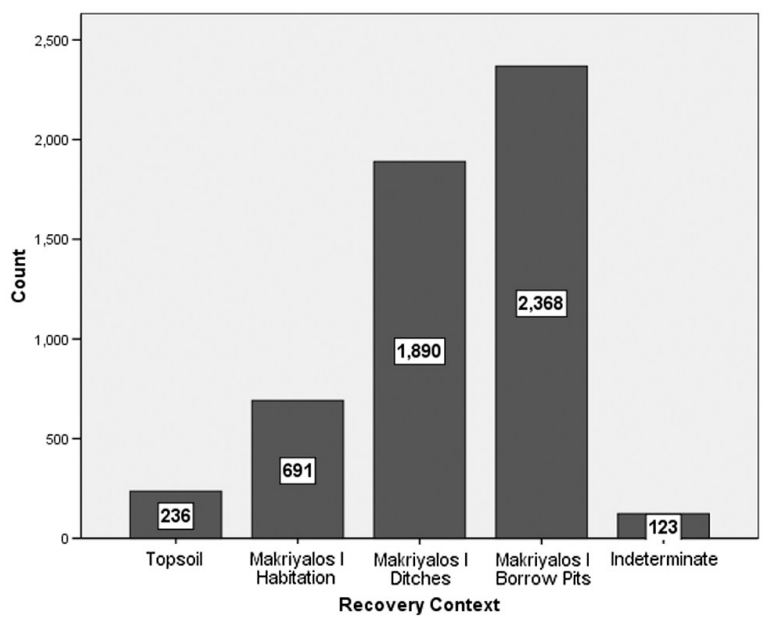

Fig. 4. The distribution of ground stone between the Makriyalos I recovery contexts.

\begin{tabular}{|lrr}
\hline \multicolumn{3}{|c}{ GENERAL OBJECT CATEGORIES } \\
\hline & Frequency & Percent \\
\hline Indeterminate & 589 & 11.1 \\
\hline Edge Tools & 932 & 17.6 \\
\hline Percussive tools & 43 & .8 \\
\hline Perforators & 28 & .5 \\
\hline Grinding/Abrasive Tools & 3486 & 65.7 \\
\hline Multiple-Use Tools & 126 & 2.4 \\
\hline Ornaments & 42 & .8 \\
\hline Miscellaneous & 62 & 1.2 \\
\hline Total & 5308 & 100.0 \\
\hline
\end{tabular}

Tab. 1. The frequency of all ground stone categories from Makriyalos $I$.

yalos (Pappa et al. 2004). Each household possessed a toolkit that supported a range of activities from plant processing to craft making. The small size of grinding slabs and of their use-faces indicates that only small amounts of plants/seeds could be processed at a time, suggesting the small scale and domestic character of these activities and of the social unit that used these tools.

\section{Discussion}

If the ground stone finds from Makriyalos I habitation contexts are compatible with the latter being arenas of domestic activity, how are the observed contrasts between habitation contexts, ditches and borrow pits to be interpreted? The spatial variation in the distribution of edge tools, grinding slabs and grinders might be interpreted in terms of discard practices, the location of different functions/activities, or patterns of curation and ownership.

\section{Discard}

In terms of discard practices, it might be expected that unbroken products of a formalised production sequence would be preferentially curated, perhaps in domestic contexts, while broken tools, those with worn-out use-faces and products of an expedient technology would be discarded, possibly in communal areas. Variation in the spatial distribution of ground stone tools would thus reflect variation in their use life.

This interpretation is consistent with the high proportions of expedient grinders in communal ditches and of carefully manufactured and maintained edge tools in habitation contexts.

Contrary to the expectations of the discard model, however, there is no difference between the three 
context types in levels of degree of wear or fragmentation, and indeed, the only three complete examples of grinding slabs in Makriyalos I come from public areas. Moreover, burnt edge tools appear with a similar frequency in all three context types. In addition, the distribution of specific tool types blurs the overall association between time investment/formality of production and depositional context: some products of a formal production sequence, such as maceheads and mortars, come only from contexts of a communal character, whereas expedient abraders and hammers are more frequent in domestic contexts. Likewise, among edge tools, those with highly polished surfaces - and thus with the greatest level of investment - are more common in the ditches than the domestic arena.

Furthermore, the study of pottery and animal bones has shown that the material accumulated in at least one of the borrow pits (Pit 212) comprises debris from particular episodes that lasted at most several months, and not long-term disposal areas, as may have been the case with the ditches (Pappa et al. 2004.22).

\section{Location of activities}

If the spatial distribution of different tool types does not represent the deposition of worn-out, broken and expedient items in selected discard areas, it might reflect the contrasting loci of different activities. Tools attest to a wide range of activities, of which grinding and the working of skin, bone and wood might all plausibly have taken place within domestic contexts, but heavy wood-working and digging may have taken place off-site. The presence of debitage in domestic contexts indicates that tool manufacture and maintenance might have been among the activities practiced in habitation contexts. A slightly higher proportion of multiple-use tools and more frequent finds of grinding slabs with wear from processing pigments offer possible hints that a wider range of activities took place in domestic than communal contexts, but both these observations are based on small samples. Overall, much the same range of tools and tasks is represented in domestic and communal contexts.

Grinding slabs were probably used not only for domestic processing of grain and minerals, but also for the large-scale processing of staple foods for communal 'feasts' taking place in or near the borrow pits. Faunal remains from Pit 212 indicate the preparation and consumption of animal-based foods on a huge scale (Pappa et al 2004.32), while the archaeo-
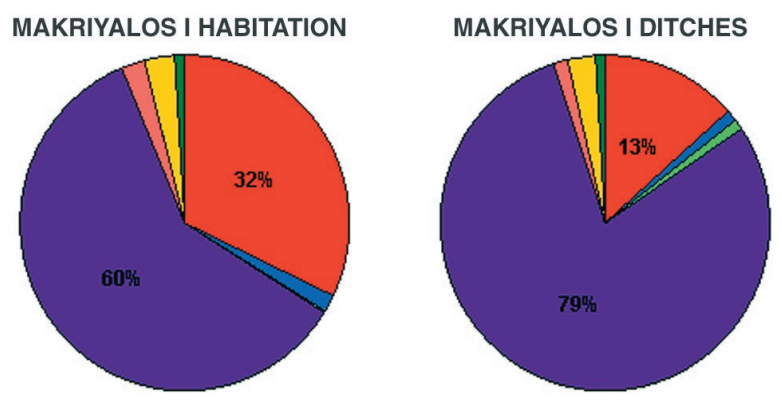

MAKRIYALOS I BORROW PITS
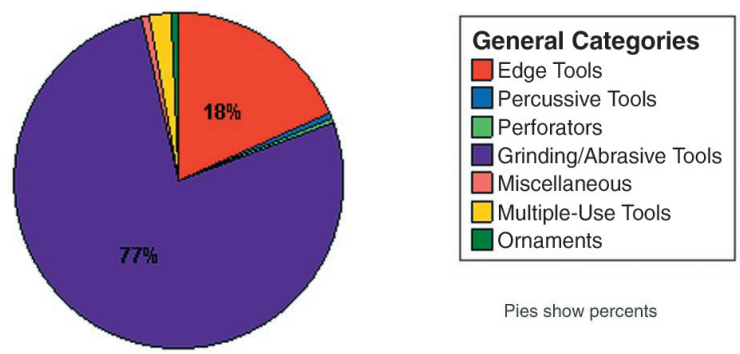

Pies show percents

Fig. 5. The distribution of general object categories between the Makriyalos I recovery contexts.

botanical data (Valamoti 2001) and the ground stone assemblage from this context might suggest the same for plant-based foods. Pit 212 accounts for $25 \%$ of all ground stone objects from Makriyalos I, while tools that could have been employed in food processing make up more than $70 \%$ of this sub-assemblage. The grinding tools may thus have been closely linked to the events taking place in or near Pit 212. The Makriyalos I grinding slabs are relatively small and hence portable and so may easily have been moved from a domestic to a communal area to meet the needs of a particular communal event (for an ethnographic parallel see Graham 1994.53-54, 70). Therefore, the value of grinding tools and the meaning of grinding activities during these events in which social relationships were forged and strengthened and group identities were shaped, can assume added connotations. Grinding activities, an otherwise everyday mundane task, acquire a different meaning when performed for larger groups of people in an event imbued with social and symbolic significance.

To a significant degree, however, observed variations in the distribution of tools cannot be explained adequately in terms of the location of activities. For example, if spatial patterning of ground stone tools primarily reflected particular activity areas, the distribution of grinding slabs should resemble, rather than contrast with, that of grinders. Likewise, the distribution of stone mortars should perhaps match that of pestles, although the use of wooden pestles 
MAKRIYALOS I HABITATION

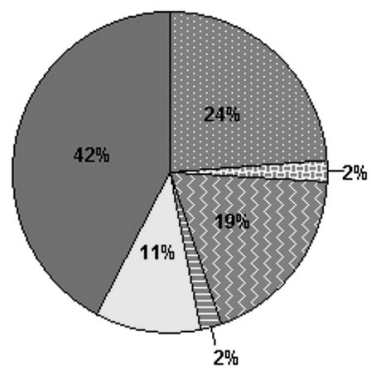

MAKRIYALOS I DITCHES

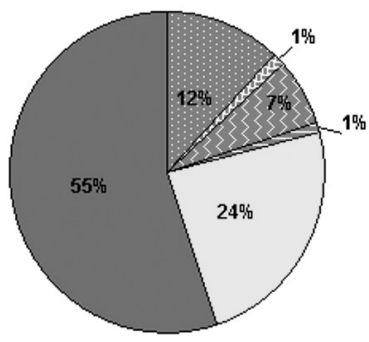

MAKRIYALOS I BORROW PITS
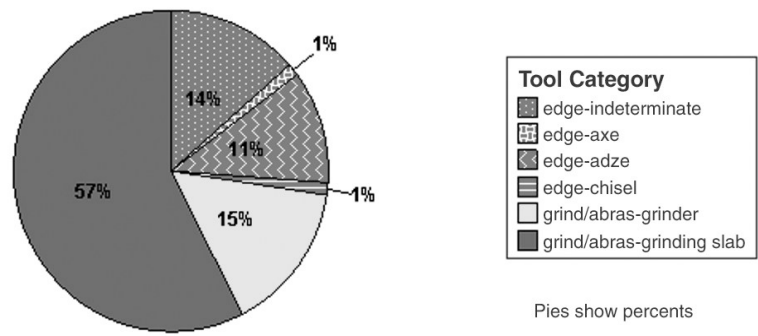

Fig. 6. The distribution of edge tools, grinding slabs and grinders between the Makriyalos I recovery contexts.

cannot be excluded. In practice, mortars occur only in communal areas, whereas pestles are encountered more frequently in habitation areas.

\section{Patterns of ownership and curation}

Another way to approach the differences in the distribution of edge and grinding tools is to consider ownership. Ethnographic studies suggest that the production and use of edge tools may be linked to individual owners (Pétrequin and Pétrequin 1993). Even worn-out or broken axes may be brought home for discard, because time invested in manufacture, aesthetic properties and multiplicity of uses engender a strong sense of attachment (Toth et al. 1992. 70). Grinding tools, on the other hand, are known ethnographically to have been shared between households (Graham 1994). The borrowing of handmills was fairly commonplace in modern Greek villages, not least because it was relatively easy for households to predict when these tools would be needed. At Makriyalos, edge tools exhibit higher levels of investment in production and refashioning than do grinding slabs and grinders, while differences in degree of polishing of edge tools may have been linked to personal aesthetics. Edge tools may also have been indispensable because they were used for a multiplicity of purposes, making them personalised objects also for practical reasons. For whatever reason, the Makriyalos assemblage includes edge tools with evidence of attempts to create a perforation - perhaps for hanging about the person.
One of these cases is a broken tool and it is tempting to suggest that the owner decided when the tool broke, to remove it from its normal context of use and prolong its life by wearing it as a pendant. The transformation of edge tools into ornaments associated with 'the body, person and personality of particular individuals' (Skeates 1995.291) has been documented in other prehistoric contexts. At Makriyalos I, however, ornaments are distributed evenly among private and public areas, suggesting that varying degrees of individual ownership of tools does not explain satisfactorily the distribution of ground stone tools within Makriyalos I.

\section{Summary}

It seems that differences in the distribution of grinding and edge tools between 'habitation' and 'communal' areas cannot not be explained satisfactorily in terms of discard practices, activity areas or ownership patterns alone, but may well be understood in terms of a combination of these. In similar discussions, archaeologists have tended to approach the discard and thus deposition of artefacts in functional/practical terms, stressing 'utilitarian considerations such as the effort involved, physical hindrances, and reuse value' (Baysal and Wright 2005.321). Yet, the act of discard may be regulated by cultural ideas, e.g., of what is regarded as waste, and socially-agreed modes of behaviour towards disposal and cleanliness (cf. Baysal and Wright 2005). Graham (1994) refers to the throwing away of still usable objects in the Rarámuri refuse area so that they can be retrieved at a later date when required. In effect, this act of disposal becomes a means of storage, and has been described as 'provisional discard' or 'passive storage' (Graham 1994.72).In addition, the value of different objects is not inherent, but can change over time according to what is perceived as culturally acceptable at that point in time. In that sense, the deposition and discard of artefacts should not be approached purely in practical or symbolic terms but, as demonstrated in the Makriyalos assemblage, as a combination of different elements and ideas that regulated the way this material was deposited.

Furthermore, we must keep in mind that the deposition of artefacts is the result of a series of episodes. These may relate to small scale localised events or to the residues of larger scale activities that either took place over a long period or involved a large number of participants. These objects represent the material culture employed in a palimpsest of specific events which gave a distinct character to the daily lives of the occupants of Makriyalos. 


\section{Conclusion}

Unlike previous studies of ground stone technology in the Neolithic of Greece, this paper follows a more contextualised approach by looking at contexts of deposition of ground stone from Late Neolithic Makriyalos. The spatial distribution of the ground stone assemblage from phase I indicates that all types of ground stone are discarded in both 'domestic' and 'communal' contexts, although edge tools are more frequent in domestic contexts and grinding tools more frequent in communal areas. This contrast in distribution between private and public areas may be interpreted as the result of a combination of discard practices, activity areas and ownership patterns. This analysis of the spatial distribution of ground stone at Makriyalos has highlighted that the discard and use of ground stone cannot be approached simply in practical terms. Rather, the deposition of artefacts may also reflect cultural ideas about the value of objects and the way these should be discarded. Therefore, generalised suggestions about the character and value of these objects need to be replaced by context-specific studies that are sensitive to the particular characteristics of specific assemblages and the communities that used and deposited them.

The recurring deposition of the same tool types in different habitation pit-groups of Makriyalos I implies that grinding and craft-production activities were widely replicated within the habitation area. This observation, paralleled by the distribution of knapped stone products during the second phase of occupation at Makriyalos (Skourtopoulou 2006) is consistent with previous suggestions for the internal organisation of Greek Neolithic communities in small independent units (households?) (Halstead 1999; Kotsakis 1999).
It has been argued elsewhere, and on other grounds, that the deposits in the ditch system and the borrow pits are actively linked to the negotiation of a communal identity (e.g., Kotsakis 1999; Triantaphyllou 1999). They do so by deploying objects that are directly linked to aspects of daily life (e.g., grinding activities) 'but provide them with a new emphasis' (Bradley 2005.119-120). In that sense, events of special significance (e.g., communal feasts) do not need to be seen in contradiction to events of daily life, for 'rituals were constructed out of the materials of domestic life' (Bradley 2005.119-120).

Clearly, much work remains to be done, but results so far contradict previous suggestions for the predominantly utilitarian character of these tools that were supposedly 'free from symbolic connotations' (Perlès 1992.149). Only in-depth and contextualised analysis of ground stone tools will allow us to gain insight into their use lives and to unravel their complex biographies.

\section{ACKNOWLEDGEMENTS}

I would like to thank the excavators of Makriyalos, Manthos Besios and Maria Pappa, for granting me permission to study the Makriyalos ground stone assemblage. I would also like to thank Maria Pappa for providing me with contextual information. I am particular grateful to my thesis supervisor, Paul Halstead, and Ben Chan for stimulating discussions and assistance with the editing of the paper. This research was generously funded by the Greek Archaeological Committee (UK), the University of Sheffield, the Sheffield Centre for Aegean Archaeology, the Sir Richard Stapley Educational Trust and the BFWG Charitable Foundation.

\section{REFERENCES}

BAYSAL A., WRIGHT K. I. 2005. Cooking, Crafts, and Curation: Ground-stone Artefacts from Çatalhöyük. In I. Hodder (ed.), Changing materialities at Catalhöyük. Reports from the 1995-99 seasons. Çatalhöyük Research Project Volume 5. BIAA Monograph No. 39. McDonald Institute for Archaeological Research, Cambridge: 307-324.

BLACKWOOD B. 1950. The Technology of a Modern Stone Age People in New Guinea. Occasional Papers on Technology, 3. Oxford University Press. Oxford.
BRADLEY R. 2005. Ritual and Domestic life in Prehistoric Europe. Routledge. London.

CARTER T., Ydo M. 1996. The chipped and ground stone. In W. G. Cavanagh, J. H. Crouwel, R. W. V. Catling and G. Shipley (eds.), Continuity and Change in a Greek Rural Landscape: The Laconia Survey. II. Archaeological Data. British School at Athens, London: 141-182. 
EDMONDS M. 1995. Stone Tools and Society. Working Stone in Neolithic and Bronze Age Britain. B. T. Batsford Ltd. London.

GRAHAM M. 1994. Mobile Farmers. An Ethnoarchaeological Approach to Settlement Organization among the Rarámuri of Northwestern Mexico. Ethnoarchaeological Series 3. International Monographs in Prehistory. Michigan.

HALSTEAD P. 1999. Neighbours from Hell? The Household in Neolithic Greece. In P. Halstead (ed.), Neolithic Society in Greece. Sheffield Studies in Aegean Archaeology, 2. Sheffield Academic Press, Sheffield: 77-95.

JONES A. 2002. Archaeological Theory and Scientific Practice. Topics in Contemporary Archaeology. Cambridge University Press. Cambridge.

KARDULIAS P. N., RUNNELS C. 1995. The Lithic Artifacts: Flaked Stone and Other Nonflaked Lithics. In C. Runnels, D. J. Pullen and S. Langdon (eds.), Artifact and Assemblage. The Finds from a Regional Survey of the Southern Argolid, Greece. Volume I. The Prehistoric and Early Iron Age Pottery and the Lithic Artifacts. Stanford University Press, Stanford, California: 74-144.

KOTSAKIS K. 1999. What Tells Can Tell: Social Space and Settlement in the Greek Neolithic. In P. Halstead (ed.), Neolithic Society in Greece. Sheffield Studies in Aegean Archaeology, 2. Sheffield Academic Press, Sheffield: 6676.

PAPPA M., BESIOS M. 1999a. The Makriyalos Project: Rescue Excavations at the Neolithic Site of Makriyalos, Pieria, Northern Greece. In P. Halstead (ed.), Neolithic Society in Greece. Sheffield Studies in Aegean Archaeology, 2. Sheffield Academic Press, Sheffield: 128-135.

1999b. The Neolithic settlement at Makriyalos, Northern Greece: preliminary report on the 1993-1995 excavations. Journal of Field Archaeology 26: 177-195.

PAPPA M., HALSTEAD P., KOTSAKIS K., UREM-KOTSOU D. 2004. Evidence for Large-Scale Feasting at Late Neolithic Makriyalos, N Greece. In P. Halstead and J. Barrett (eds.), Food, Cuisine and Society in Prehistoric Greece. Sheffield Studies in Aegean Archaeology, 5. Oxbow Books, Oxford: $16-44$.

PERLÈS C. 1992. Systems of Exchange and Organization of Production in Neolithic Greece. Journal of Mediterranean Archaeology 5: 115-164.

2001. The Early Neolithic in Greece. The first farming communities in Europe. Cambridge World Archaeology. Cambridge University Press. Cambridge.
PÉTREQUIN P., PÉTREQUIN A.-M. 1993. Écologie d'un outil: la hache de pierre en Irian Jaya (Indonésie). Monographie du CRA 12. CNRS ÉDITIONS. Paris.

SEFERIADES M. 1992. L'outillage: La pierre polie. In R. Treuil (ed.), Dikili Tash. Village Préhistorique de Macédoine Orientale. Vol. 1. Fouilles de Jean Deshayes (1961-1975). BCH Suppl. XXIV. École Française d' Athènes, Athènes: 84-99.

SKEATES R. 1995. Animate objects: a biography of prehistoric 'axe-amulets' in the central Mediterranean region. Proceedings of the Prehistoric Society 61: 279-301.

SKOURTOPOULOU K. 2006. Questioning Spatial Contexts: The Contribution of Lithic Studies as Analytical and Interpretative Bodies of Data. In D. Papaconstantinou (ed.), Deconstructing Context. A Critical Approach to Archaeological Practice. Oxbow Books, Oxford: 50-78.

TOMKINS P. 2004. Filling in the 'Neolithic Background': Social Life and Social Transformation in the Aegean before the Bronze Age. In J. C. Barrett and P. Halstead (eds.), The Emergence of Civilisation Revisited. Sheffield Studies in Aegean Archaeology, 6. Oxbow Books, Oxford: 38-63.

TOTH N., CLARK D., LIGABUE G. 1992. The Last Stone Ax Makers. Scientific American 267: 66-71.

TRIANTAPHYLLOU S. 2001. A Bioarchaeological Approach to Prehistoric Cemetery Populations from Central and Western Greek Macedonia. BAR International Series 976. British Archaeological Reports. Oxford.

TSORAKI C. forthcoming. 'Shiny and colourful': Raw Material Selection and the Production of Edge Tools in Late Neolithic Makriyalos, Greece. In A. Saville (ed.), Flint and Stone in the Neolithic. Neolithic Studies Group Seminar Papers. Oxbow Books. Oxford.

in prep. Neolithic Society in Northern Greece: The Evidence of Ground Stone Assemblages. PhD Thesis. University of Sheffield.

VALAMOTI S.-M. 2004. Plants and people in Late Neolithic and Early Bronze Age Northern Greece. An archaeobotanical investigation. BAR International Series 1258. Archaeopress. Oxford.

WINN S., SHIMABUKU D. 1989. Bone and Ground Stone Tools. In M. Gimbutas, S. Winn and D. Shimabuku (eds.), Achilleion. A Neolithic Settlement in Thessaly, Greece, 6400-5600 BC. Institute of Archaeology, University of California, Los Angeles, California: 259-272.

WRIGHT K. 1992. A classification system for ground stone tools from the prehistoric Levant. Paléorient 18: 53-81. 